\title{
Study on Japan's Population Aging and Its Impact on Economy
}

\author{
Jingya Zhou \\ Beijing University of Posts and Telecommunications, Beijing, 100876
}

Keywords: Japanese; population aging; economy; impact

\begin{abstract}
The problem of population aging has become a global topic. It is an inevitable trend in the development of human society and an inevitable result of the improvement of productivity. Since the beginning of the 21st century, developed countries such as Japan, France, and the United States, as well as developing countries such as China and Cuba, are facing the impact of economic growth and social development brought about by the aging of the population. This paper is based on China's national conditions, that is, the elderly population is large, the elderly population is growing fast, and the aging trend is obvious. From the aging of the population to the economic growth of labor costs, labor productivity and labor participation rate, savings rate and human capital accumulation, the effects of factors are used for theoretical and empirical analysis.
\end{abstract}

\section{Introduction}

After the Second World War, Japan's economy and society have undergone great changes. This series of changes has had a great impact on Japan's population changes. In 1947, Japan's total population was 78.1 million. In 1967, it exceeded 100 million. In 1970, Japan's population reached 103.72 million, which is three times the population of the Meiji Restoration. In the 30 years since 2000, Japan's population growth rate has been slow, with an increase of only 23.2 million to 126.92 million. In 2005, Japan's population experienced negative growth, with a total population of 127.768 million, a decrease of 19,000 from the previous year. According to data released by the Ministry of Internal Affairs and Communications of Japan, as of October 1, 2008, the total population of Japan was 127.692 million (including a male population of 62.251 million and a female population of 654.41 million), a decrease of 7.9 from the previous year. Tens of thousands of people have experienced negative population growth again after three years. The total female population has decreased for the first time since 1950, and the total male population has decreased for four consecutive years. According to statistics from the Statistics Bureau of the Ministry of Internal Affairs and Communications of Japan, the population of Japan decreased to 127.547 million in 2009, a decrease of 221,000 compared with 2005.

\section{The Process of Population Aging and Its Current Status}

Due to the impact of the economy, Western values and social ethics, the population has gradually transitioned to low birth, low death, and low growth. Japan's birth rate has been declining except for the two "baby fever" periods. According to the National Institute of Social Security and Population Research, the number of elderly people aged 65 and over in Japan increased from 4.109 million in 1950 to 281.16 million in 2008, an increase of 241.07 million in 58 years. The average annual increase is 482,140, and the proportion of the population aged 65 and over to the total population has also increased from $4.9 \%$ to $22.1 \%$, an increase of nearly 3.5 times. Especially since 1975 , due to the rapid decline in the birth rate, the rapid development of Japan's population aging has attracted the attention of the Japanese population and the world. From 1950 to 1970, the proportion of elderly people aged 65 and over in Japan increased by 2.2 percentage points, and the population increased from 4.109 million to 73.31 million. The growth rate is not very fast. In 1970, Japan's population over 65 years old accounted for $7.1 \%$ of the total population, marking Japan's entry into the aging population. The direct decline in fertility levels has the direct consequence of accelerating the process of population ageing. In 1980, compared with 1970, the number of elderly people aged 65 
and over increased by 3.316 million, and the proportion of the population also increased by 2 percentage points. The average life expectancy of the population also rose from 74.66 to 78.76 . Since the 1980s, Japan's aging population has entered a stage of accelerated development. In 1990, the proportion of the elderly aged 65 and over was $12.1 \%$, rising to $17.4 \%$ in 2000 , reaching $20.2 \%$ in 2005 and $22.1 \%$ in 2008. It can be seen that the aging of Japan's population has shown an accelerated development under the combined effect of population birth rate and population mortality. The aging of the population not only represents an absolute increase in the number of elderly people in a country or region, but also reflects the age structure of their population. It shows the changes in the age structure of the Japanese population since 1980. It can be seen that from 1980 to 2005, the aging population of Japan has more than doubled in the 25-year period, reaching $20.09 \%$, that is, one out of every five people has an elderly population over 65 years old, and has become the proportion of the population over 65 years old in the world. The country that first reached 20\%. In 2008, Japan's elderly population over 65 years old has reached $22.1 \%$. According to the National Institute of Safeguards and Population's prediction of the aging of the world's major countries, Japan is not only the country with the highest degree of population aging, but also the development of population aging. One of the fastest countries, second only to Singapore and South Korea.

\section{Impact on Economic Development}

The natural changes in Japan's population are mainly characterized by a sharp decline in fertility, and the aging of Japan's young children has continued to develop due to long-term low fertility levels. Combined with the current population age structure in Japan and the results of future population projections, it can be clearly seen that population aging and changes in age structure will have a multifaceted impact on the Japanese economy. First, the impact of population ageing on social production. The production and reproduction of any society is premised on the combination of means of production and labor in a certain mode of production. Although modern economics has changed the definition of factors of production, in the final analysis, the most basic factors of production are still Labor and capital. In the 1990s, Japan's working-age population peaked and then gradually declined. By 2008, the working-age population accounted for $64.45 \%$ of the total population. Although the unemployment rate in Japan has gradually declined since the beginning of the 21st century, on the one hand, this phenomenon has shown that employment pressure in Japan has eased, but on the other hand, for Japan, the fertility rate has remained at a low fertility level for a long time, and the population growth has been slow. Even negative growth has occurred and the population is aging, which indicates that the shortage of labor resources in Japan is serious. According to the forecast of the Japanese population forecasting agency, from 2010 to 2030, the working-age population in Japan will be reduced from 81.28 million to 64.04 million. In 2050, this figure will further continue to decrease to 49.297 million, accounting for the total. The proportion of the population has also dropped from $63.9 \%$ to $51.8 \%$, especially in rural areas, construction sites, elderly nursing homes, etc., where labor resources are seriously lacking. Adequate labor resources are the source of social and economic development. Insufficient labor supply will inevitably lead to slow economic growth. On the other hand, with the long-term economic downturn and aging of the Japanese economy, many Japanese are worried that they will be old when they are old, and their concerns about the future will keep the Japanese savings rate at a high level. , which in turn affects the Japanese consumer market.

Secondly, the dependency coefficient is constantly rising, and the burden of social support is increasing. According to the statistics of the Ministry of Internal Affairs and Communications of Japan, the proportion of children and children aged 65 and over in the total population in 2007 was $13.53 \%$ and $21.49 \%$, respectively, and the coefficient of child rearing and the elderly population were 20.77 and 33.08, respectively. According to the forecast, the child rearing coefficient and the old-age dependency coefficient of Japan in 2055 are 16.4 and 79.4, respectively. The decline in the child dependency coefficient is mainly due to the decline in the proportion of children and adolescents, which is faster than the decline in the proportion of the working-age population. The 
large increase in the dependency factor is due to the decline in the proportion of the working-age population while the proportion of the elderly population is rising. Therefore, the problem of raising the burden of Japanese society, especially the elderly, is becoming more and more serious, which will have a certain impact on Japan's current pension security system. The decline in the working-age population and the slow increase in the elderly population have led to a slow increase in the burden of social support. It is necessary to point out that the increase in social security expenditures accompanying the aging society will have a great impact on the living standards of the people. By 2020, the number of elderly people over the age of 75 will account for more than half of the elderly population, and will increase year by year. By 2055, the proportion of the elderly population over 75 years old accounts for $26.5 \%$ of the total population, accounting for 65.43 of the elderly population over 65 years old. \%, that is, one out of every four people is over 75 years old. The development of aging has not only increased the burden on employed people, but also faced enormous challenges for the Japanese nursing system. The increase in the proportion of the elderly over the age of 75 means that the elderly are already high, suffering from chronic diseases, debilitating, unable to take care of themselves or partially unable to take care of themselves. Must rely on the assistance activities of others. Along with the declining birthrate and the prolongation of life expectancy, the increase in the proportion of senior citizens will lead to a negative impact on social and economic development by a series of social security systems such as pensions, medical care and welfare.

\section{Policy Measures to Deal with Population Aging}

The deepening of Japan's aging has deeply affected the composition of the Japanese labor force. The proportion of the working population of the elderly has increased year by year, which will inevitably lead to an increase in the social burden, if the current economic development rate is preserved. To reduce the social security expenditures of the elderly and adjust the fiscal expenditure policy, this may bring a better effect to the Japanese economy in the short term, but in the long run, it will inevitably affect the further development of the economy and affect social stability. Harmonious Development. At this time, it is necessary to improve the employment structure and employment system, give full play to the advantages of the elderly group, establish an old-age employment relationship suitable for the elderly, maximize the social output of the elderly, and reduce social consumption. Therefore, regarding the aging problem in Japan, what the government should do is to mobilize the vitality and enthusiasm of the elderly group, extend its working capacity, create more social benefits, thereby reducing the social consumption of the elderly and reducing the social age of the elderly. Dependence. 'Month is also the experience of the economic development country, it is worthy of our reference.

The intensification of Japan's aging has brought great impact on traditional family support, and the support for the elderly has gradually shifted from the traditional family to the social security system. However, as Japan's aging population intensifies and Japan's labor force declines, Japan's spending on old-age insurance costs has increased year by year. This has caused Japan's fiscal deficit to appear in successive years. Therefore, the Japanese government hopes that traditional family pensions will be restored. With the function of family pension, it is possible to truly solve the problem of aging in Japan. At the same time, family pensions are more efficient than pensions in the government insurance system. . Because the elderly need a basic material life guarantee, they also need a rich spiritual life. When the elderly walk into the welfare home for the elderly, there is always a feeling of being abandoned by the family. This is less accepted in a country like Japan, which is deeply influenced by Confucianism. The elderly hope that their old age will live with their sons, daughters, grandchildren and granddaughters, and enjoy the family's happiness. 'In Japan, although after decades of development, a relatively complete social security system for the elderly has been established, this does not mean that traditional family pensions are no longer welcome. In fact, the establishment of a social security system for the elderly in Japan can be given to families. The greatest support for the elderly, the elderly enjoy family fun in the family, and receive the corresponding benefits from various insurance systems to reduce the burden of family pension, 
which is also very helpful for the return of Japanese traditional culture.

\section{Conclusion}

The impact on human capital is negative, that is, the deeper the population is aging, the growth rate of total human capital shows a downward trend. Therefore, in order to alleviate the impact of population aging on economic growth, we need to adopt corresponding policy recommendations and measures. For the primary stage of China's transition from a planned economy to a market economy, the most important thing is to optimize the industrial structure and adjust the direction of product demand. Fundamentally accelerate the transformation of economic growth mode, and rely on the increase of factor input as soon as possible to increase the economic growth rate of economic growth caused by the increase of factor productivity.

\section{References}

[1] Wang Wei. The changing trend of Japan's population structure and its impact on society [J]. Japanese Journal, 2003, (7): 127-130.

[2] Gan Hongqing, Li Yan, Guo Sijia. The impact of Japan's population reduction on the economy and its coping strategies [J]. Modernization of Shopping Malls, 2007, (5): 144.

[3] Zhou Yun. Social Policy and the Development of Japanese Population [J]. Journal of Population Science, 2008, (5): 3 -7.

[4] Tian Xianglan. The problem of insufficient labor force in Japan and its solutions [J]. Social Work (Theoretical Edition), 2009, (1): 55 -57.

[5] Chen Liang. The revision of the Japanese nursing insurance system and the participation of non-profit organizations in the elderly [J]. Journal of Population Science, 2009, (2): 53-59. 